\title{
CLOSED LOOP FRACTIONAL ORDER PID CONTROLLED MULTILEVEL STATCOM FOR TEN BUS SYSTEM
}

\author{
K. Balaji Nanda Kumar Reddy ${ }^{1} \&$ Dr. V.C. Veera Reddy ${ }^{2}$
}

Abstract-DSTATCOM is capable of improving the voltage of weak buses in distribution systems. The objective of this research work is to reduce THD in the output of STATCOM using multilevel concept. This paper deals with Design, Modeling and Simulation of closed loop FOPID controlled Ten Bus System using Matlab Simulink. The modelling of DSTATCOM and control of THD using multilevel DSTATCOM becomes an important issue. Ten Bus Distribution Systems (TBDS) with PI and FOPID Controlled STATCOMs are modulated, simulated and the results are presented here. The Simulation Results indicate that the settling time and steady state error are reduced by introducing FOPID controller. The STATCOMs are introduced at the weak buses and the improvement in time response was observed.

List of Abbreviations

TBDS - Ten Bus Distribution System

FLSS - $\quad$ Five level STATCOM system

SLSS - $\quad$ Seven level STATCOM system

THD $\quad$ - $\quad$ Total Harmonic Distortion

FOPID - $\quad$ Fractional Order PID Controller

\section{INTRODUCTION}

The standard predictable state consistent quality investigations and transient robustness consider the dynamic power stream and power edge and generally expect relentless getting and sending end transport voltage. The receptive power stream and voltage fall amid overwhelming current stream is ignored. This approach could not explain the several black-outs in USA, Europe, Japan etc. during the last quarter of the twentieth century. The blackouts were due to voltage collapse. During voltage collapses, the bus voltage starts falling and as a result power transfer through the transmission line starts reducing resulting in ultimate voltage collapse and loss of system stability of entire network. That is the reason voltage security ponders have gotten more consideration and have obtained a fundamental place in power framework thinks about. Voltage fall wonders occur where receptive power administration is lacking.

The application of power electronics in the electric power transmission plays an important role to make the system more reliable, controllable and efficient [1]. Because of deregulation, natural enactments and cost of development, it is ending up noticeably progressively hard constructing new transmission lines. Thus it is essential to fully utilize the capacities of the existing transmission system. The Flexible AC Transmission System (FACTS) has become a popular solution to our large/over extended power transmission \& distribution system. FACTS devices are proving to be very effective in using the full transmission capacity while increasing power system stability, transmission efficiency and maintained power quality and reliability of power system. These devices are mainly based on either voltage source converter (VSC) or current source converter (CSC) and have fast response time. As an important member of FACTS devices family, STATCOM has been at the centre of attention and the subject of active research for many years. STATCOM is a shunt associated gadget that is utilized to give receptive power remuneration to a transmission line.

This controller can either absorb or inject reactive power whose capacitive or inductive current can be controlled independent to the AC line voltage. Thus, STATCOM can enhance the transmission line load ability by extending the MW margin and improves the oscillation of voltage transients through efficient regulation of the transmission line voltage at the point of connection [1]-[3].

The device is connected to a load bus with a converter transformer. The displaying of shunt controller and testing is reproduced in the MATLAB/Simulink condition. The controller is spoken to as piece chart that presents down to earth electronic model of shunt controller. PID controller is used to control the current injection at the connection point by varying the desired parameters, one is Modulation Index (AM) and another is power angle $(\delta)$. Mainly there are four loop tuning methods for a PID controller; those are manual tuning, Ziegler-Nichols, Software Tools and Cohencoon Method.

Firstly, Ziegler-Nichols method is chosen for loop tuning and then manual tuning is applied to the PID controller by trial and error method to take its performance at optimum level. Actually, there are four diverse control procedures for a STATCOM

\footnotetext{
${ }^{1}$ Research Scholar, Rayalaseema University, Kurnool, Andhra Pradesh, India

${ }^{2}$ Department of Electrical and Electronics Engineering, Annamacharya Institute of Technology \& Sciences, Tirupati, Andhra Pradesh, India
} 
controller, coordinate control, decoupling control, cross control and framework control. The immediate control strategy is utilized here to control the yield of shunt associated FACT device.

\subsection{Basic Configuration and Principle of operation}

Basically, shunt connected FACTS device can be realized by either a VSC or a CSC [4]. But the VSC topology is preferred because CSC topology is more complex than VSC in both power and control circuits. In CSC such as GTO (Gate Turn Off Thyristor) is used, a diode has to be placed in series with each of the switches. This almost doubles the conduction losses compared with the case of VSC. The DC link energy storage element in CSC topology is inductor where as that in VSC topology is a capacitor. Thus, the efficiency of a CSC is expected to be lower than that of a VSC [6]-[9]. The modelled STATCOM using VSC topology is being used in the test system to supply reactive power to increase the transmittable power and to make it more compatible with the prevailing load demand. Thus, the shunt connected FACTS device should be able to minimize the line over voltage under light load condition and maintain voltage levels under heavy load condition. Two VSC technologies can be used for the VSC. One of them, VSC is constructed with IGBT/GTO-based SPWM inverters. This type of inverter uses sinusoidal Pulse-Width Modulation (SPWM) technique to synthesize a sinusoidal waveform from a DC voltage source with a typical chopping frequency of a few kilohertz.

Harmonic voltages are cancelled by connecting filters at the AC side of the VSC. This type of VSC uses a DC link voltage Vdc. Output voltage is varied by changing the modulation index of the SPWM modulator. Thus modulation index has to be varied for controlling the reactive power injection to the transmission line. In another type VSC is constructed with GTObased square-wave inverters and special interconnection transformers. Typically four three-level inverters are used to build a 48-step voltage waveform. Special interconnection transformers are used to neutralize harmonics contained in the square waves generated by individual inverters. In this type of VSC, the fundamental component of output voltage is proportional to the voltage $\mathrm{V}_{\mathrm{dc}}$. Therefore $\mathrm{V}_{\mathrm{dc}}$ has to be varied for controlling the reactive power.

The shunt controller is like a current source, which draws from or injects current into the system at the point of connection. The shunt controller may be variable impedance, variable source or a combination of these [10]. Variable shunt impedance associated with the line voltage causes a variable current stream and thus speaks to infusion of current into the line. For whatever length of time that the infused current is in stage quadrature with the line voltage, the shunt controller just supplies or devours receptive power. When system voltage is low, the STATCOM generates reactive power (STATCOM capacitive). When system voltage is high, it absorbs reactive power (STATCOM inductive).

The variation of reactive power is performed by means of a VSC connected on the secondary side of a coupling transformer. The VSC uses forced-commutated power electronic devices (GTOs, IGBTs or IGCTs) to synthesize a voltage V2 from a DC voltage source. Any other phase relationship will involve handling of real power as well [11]. So, the shunt controller is therefore a good way to control the voltage at and around the point of connection through injection of reactive current (leading or lagging) alone or a combination of active and reactive current for a more effective voltage control and damping of voltage dynamics [12].

The above literature does not deal with comparison of PI and FOPID based STACOMs in ten bus radial distribution system. This work proposes FOPID controller for STATCOM of ten bus system. The real power (P) and reactive power $(\mathrm{Q})$ are expressed as follows:

$$
\begin{aligned}
& \mathrm{P}=\frac{\mathrm{V}_{1} \cdot \mathrm{V}_{2}}{\mathrm{X}} \operatorname{Sin} \delta \\
& \mathrm{Q}=\frac{\mathrm{V} 2}{\mathrm{X}} \underset{(2)}{\left(\mathrm{V}_{2}\right.}
\end{aligned}
$$

\section{SIMULATION RESULT}

Open loop ten bus system with change in load is shown in Fig 3.1. The receiving end voltage is shown in Fig 3.2 and its peak value is $6 \mathrm{KV}$. The RMS receiving end voltage is shown in Fig 3.3 and its value is $4300 \mathrm{~V}$. The real and reactive powers are shown in Fig 3.4 and real power is $7 * 10^{4}$ watts and reactive power is 12500 VAR. 


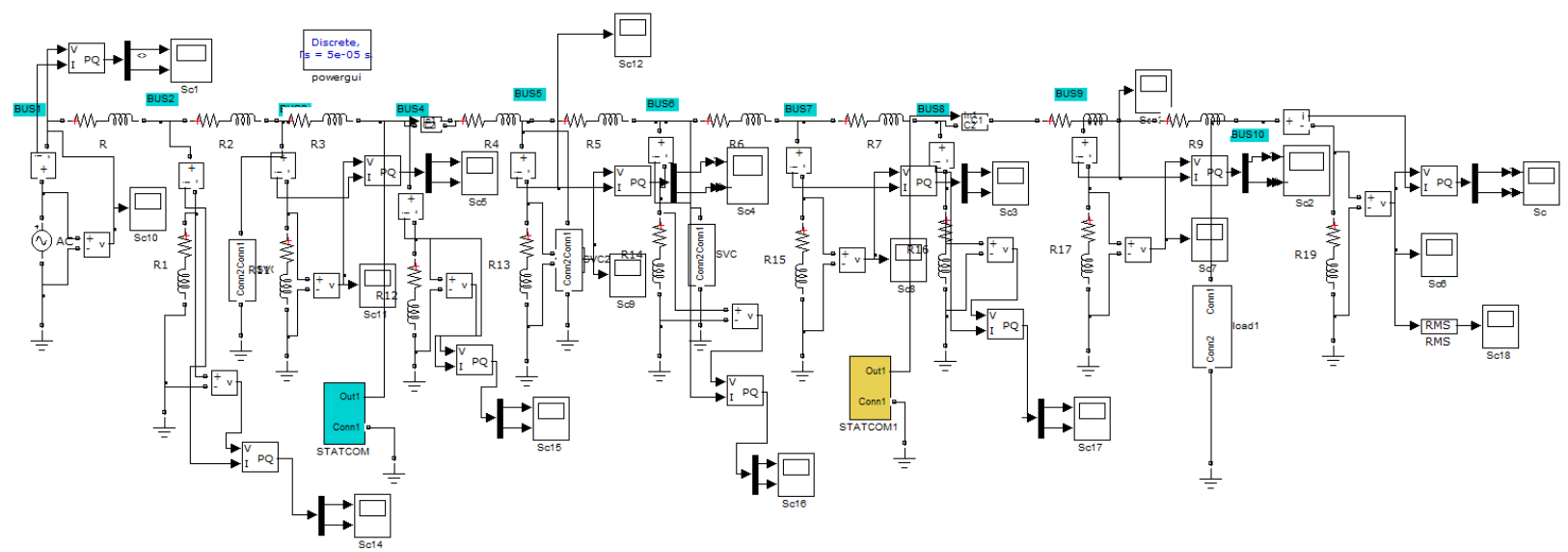

Fig 3.1 Open loop Ten Bus system with change in load

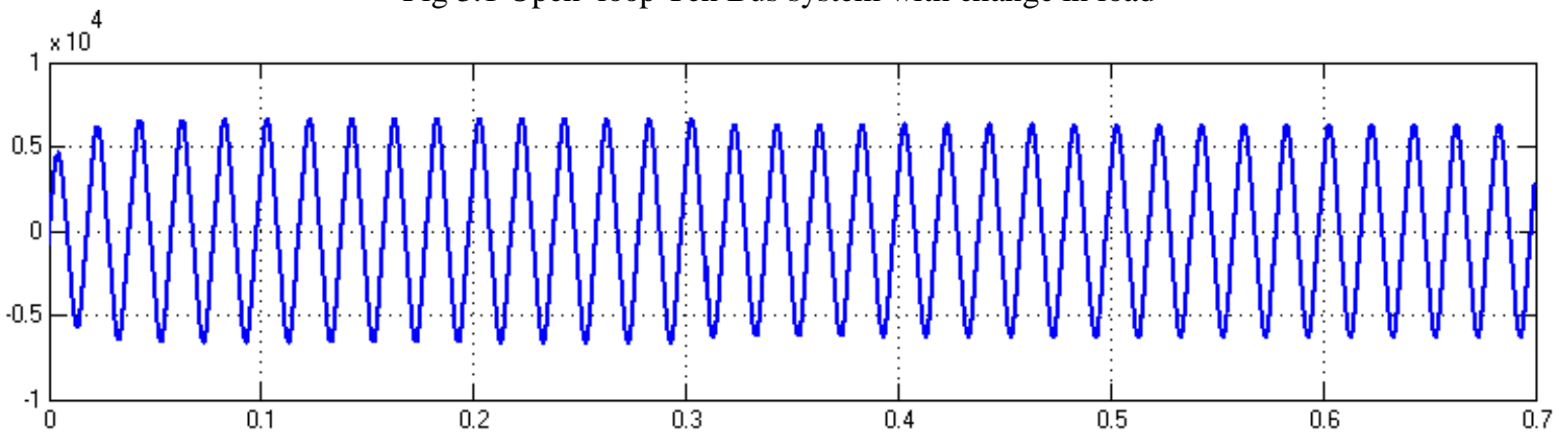

Fig 3.2 Receiving End voltage

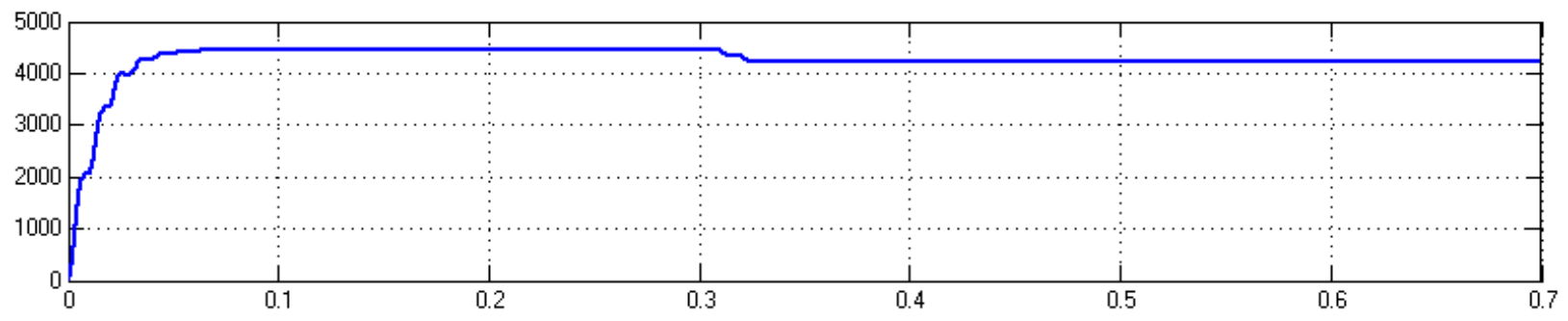

Fig 3.3 RMS Receiving End voltage
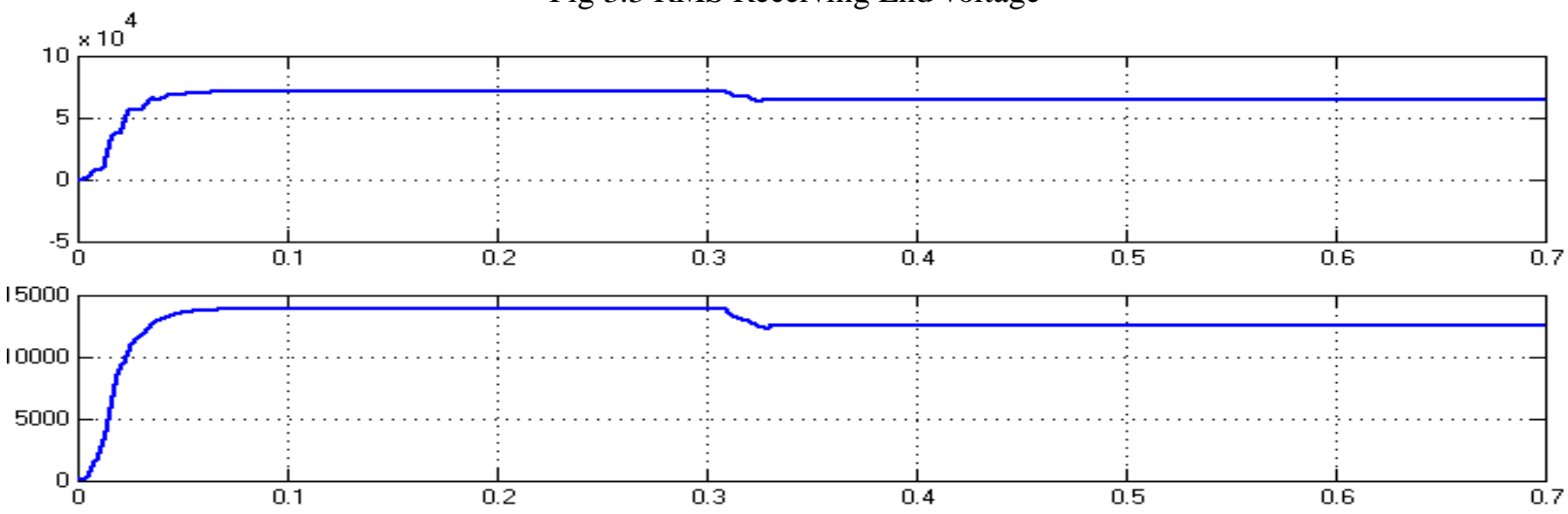

Fig 3.4 Real \& Reactive powers

Closed loop ten bus system with PI controller is shown in Fig 4.1. The receiving end voltage is shown in Fig 4.2 and its peak value is $7000 \mathrm{~V}$. The RMS receiving end voltage is shown in Fig 4.3 and its value is $4300 \mathrm{~V}$. The real and reactive powers are shown in Fig 4.4 and real power is $7 * 10^{4}$ watts and reactive power value is 12500 VAR. 


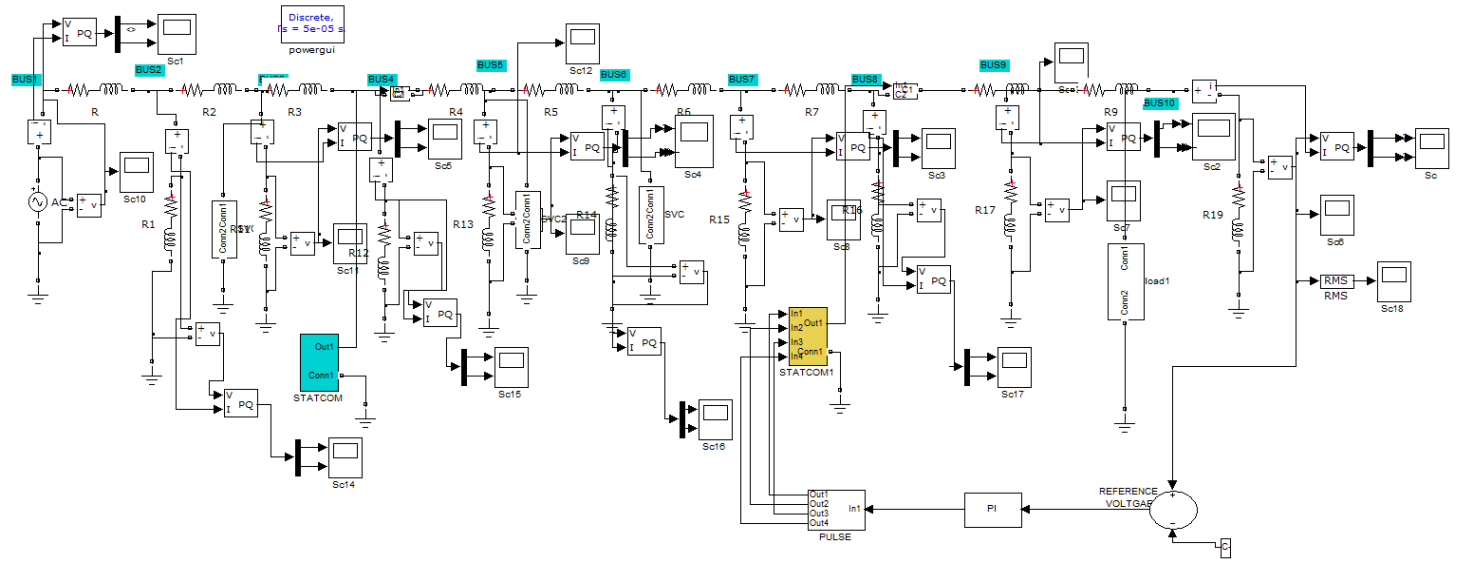

Fig 4.1 Closed loop Ten bus system with PI controller

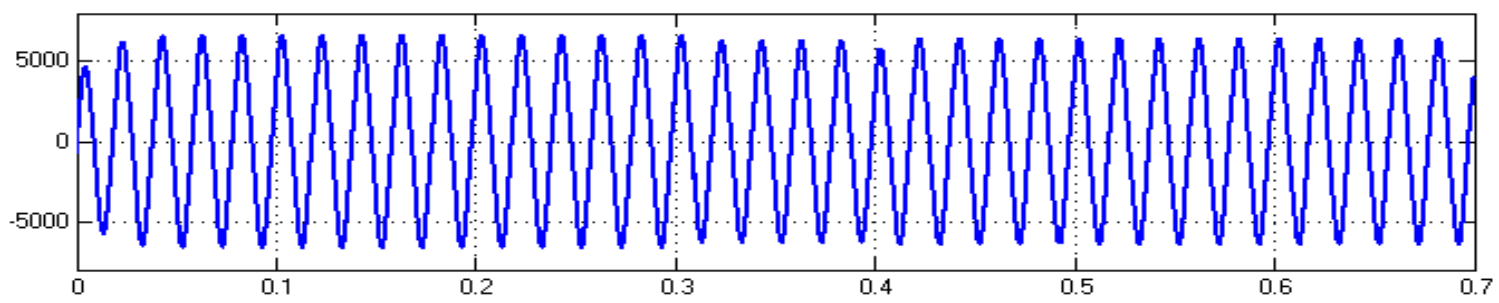

Fig 4.2 Receiving End voltage

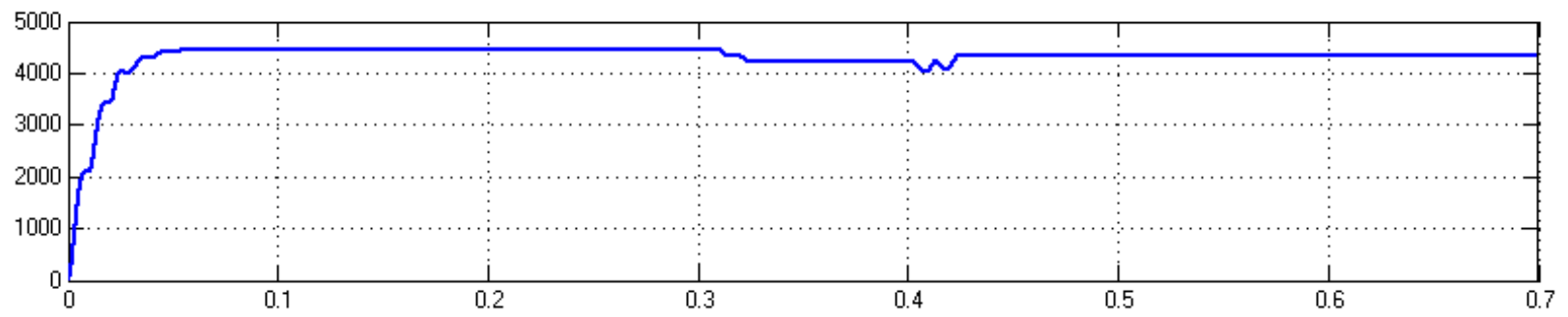

Fig 4.3 RMS Receiving End voltage
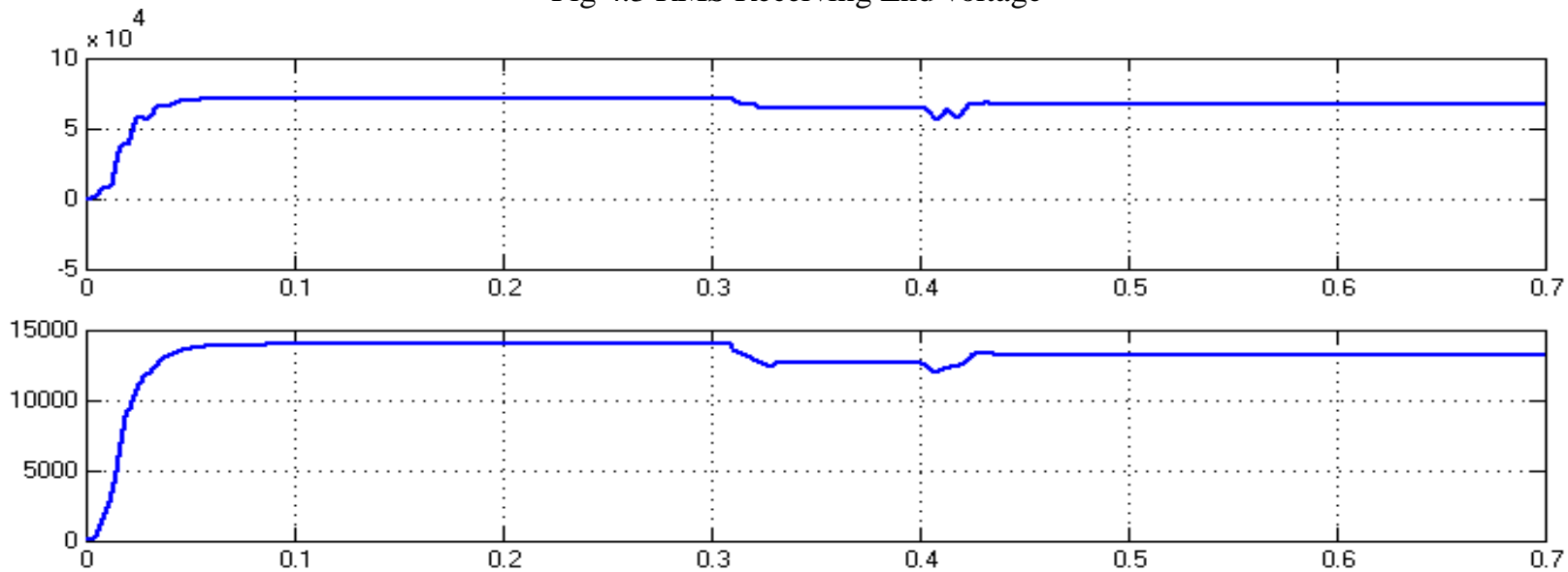

Fig 4.4 Real \& Reactive powers

Closed loop tenbus system with FOPID controller is shown in Fig 5.1. The receiving end voltage is shown in Fig 5.2 and its peak value is $7000 \mathrm{~V}$. The RMS receiving end voltage is shown in Fig 5.3 and its value is $4300 \mathrm{~V}$. The real and reactive powers are shown in Fig 5.4. The real power value is $8 * 10^{4}$ watts and reactive power value is 13500 VAR. The comparison of time domain parameters is given in Table-1. 


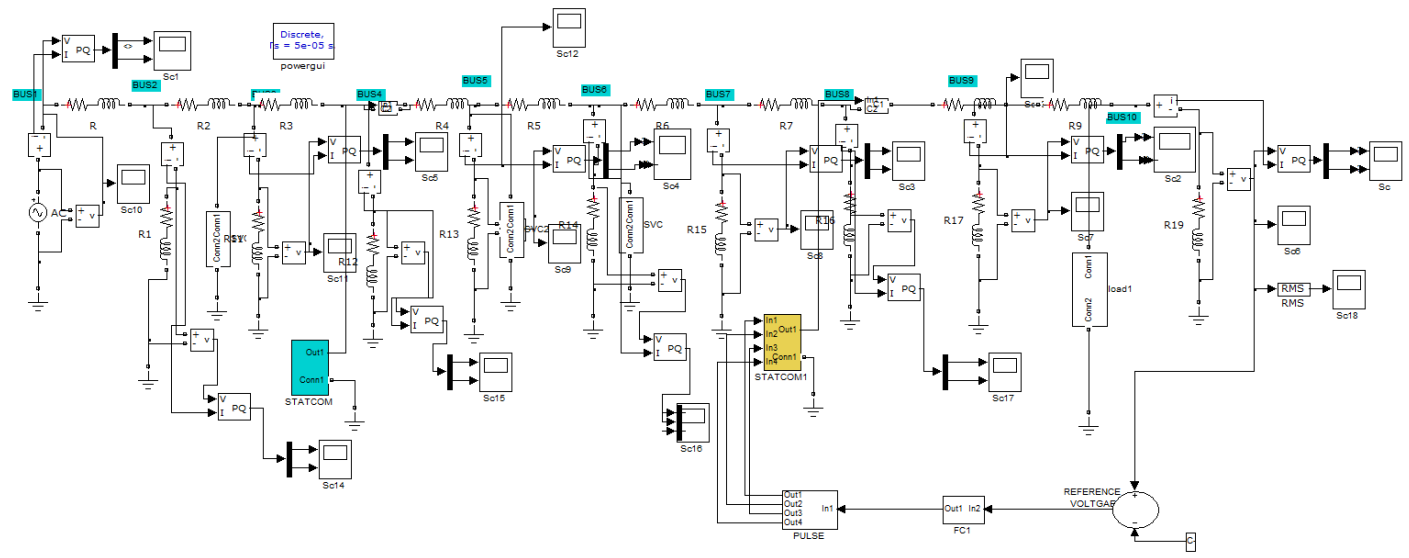

Fig 5.1 Closed loop Ten bus system with FOPID controller

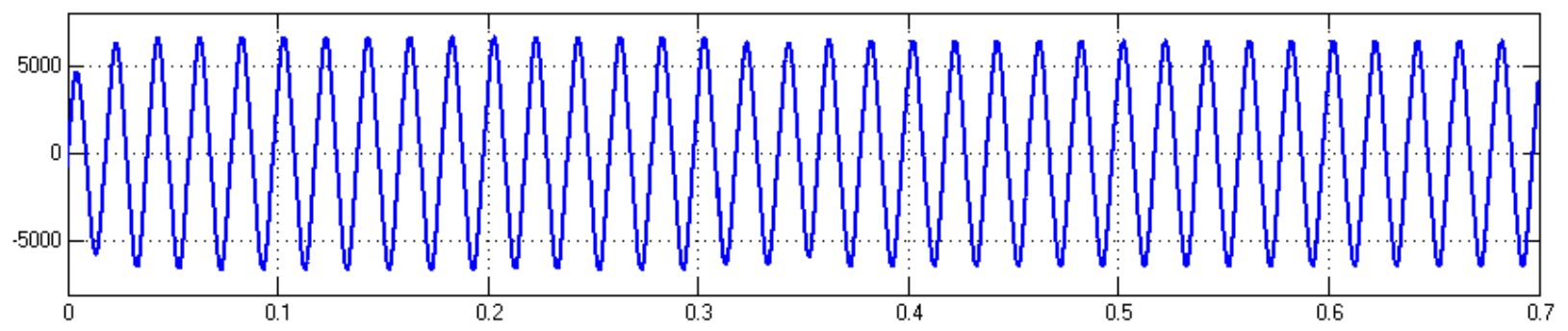

Fig 5.2 Receiving End voltage

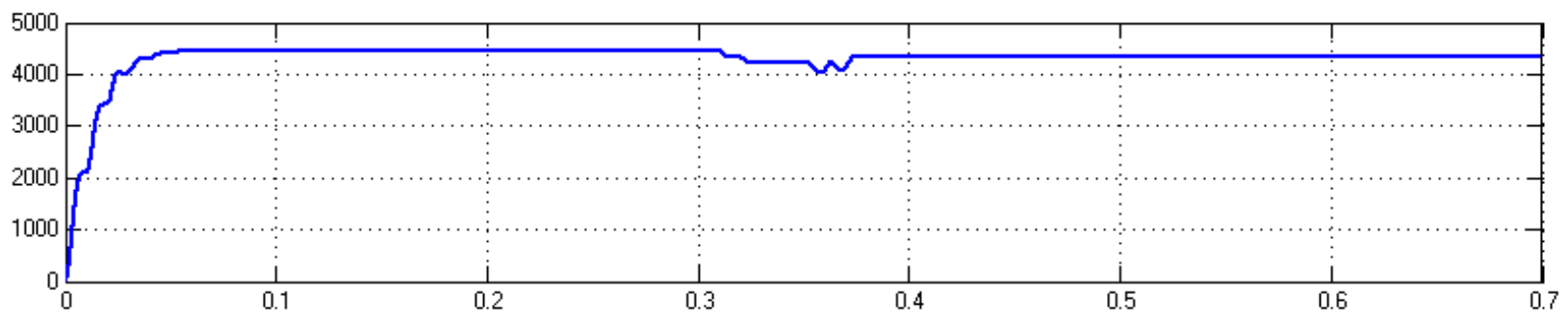

Fig 5.3 RMS Receiving End voltage

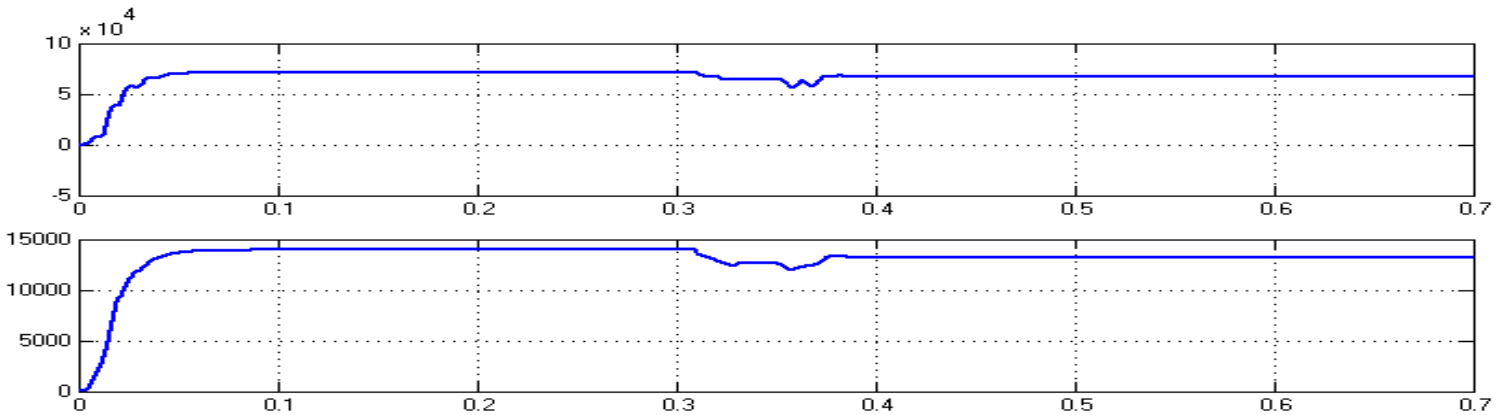

Fig 5.4 Real \& Reactive power

Table-1 Comparison Time Domain Parameters

\begin{tabular}{|l|l|l|l|l|}
\hline Type of Controllers & Rise time (s) & Peak time (s) & Settling time (s) & $\begin{array}{l}\text { Steady state } \\
\text { error (V) }\end{array}$ \\
\hline PI & 0.33 & 0.37 & 0.42 & 5.6 \\
\hline FOPID & 0.32 & 0.34 & 0.37 & 2.4 \\
\hline
\end{tabular}




\section{CONCLUSION}

The conclusions derived from simulation work on PI \& FOPID presented in previous section has been summarized. Ten Bus Distribution System was successfully modelled and simulated using the blocks of Simulink and the results are described. Voltage Sag was created by adding extra load and it is compensated by using STATCOM. The results obtained in this paper are clear example of improvement in power quality using multilevel STATCOM. The settling time is as low as $2.4 \mathrm{~V}$. The advantages of proposed system are reduced heating of distribution lines and improved voltage profile. The disadvantage of STATCOM is that it requires large DC Capacitor at the input and eight switches per phase.

The scope of the present work is to study the performance of SLSS in ten bus system using FOPID controller. The performance of SLSS with in thirty bus system will be studied in future. Closed loop controlled SLSS with will be studied in future.

\section{REFERENCES:}

[1] Ricardo D.M., Juan M.R. and Ruben T.O., 2005. Three-phase multi-pulse converter STATCOM analysis. International Journal of Electrical Power \& Energy Systems 27(1): 39-51.

[2] Moran, P.D., Ziogas, L.T., Joos, G. and Hingorani, N.G., 1989. Analysis and design of a three-phase current source solid- state var compensator. IEEE Transactions on Industrial Application 25(2): 356-365.

[3] Gyugyi, L., 1994 Dynamic compensation of AC transmission lines by solid-state synchronous voltage sources. IEEE Transactions on power Delivery 9(2): 904-911.

[4] Gyugyi, L., Schauder, C.D., Williams, S.L., Reitman, T.R., Torgerson, D.R., and Edris, A., 1995. The unified power flow controller: A new approach to power transmission control. IEEE transactions on power delivery 10(2): 1085-1097.

[5] Ye, Y.,Kazerani, M., and Quintana, V.H.2005. Current-Source Converter, Based STATCOM:Modeling and control. IEEE Tansactions on Power Delivery 20(2):795-800.

[6] Tavakoli Bina, M., Eskandari, M.D. and Panahlou, M., 2005. Design and installation of a \# $250 \mathrm{kV}$ ArD-STATCOM for a distribution substation. Electric Power Systems Research 73(3): 383-391.

[7] Puleston, P.F., Gonzalez, S.A. and Valenciaga, F., 2007. A STATCOM based variable structure control for power system oscillations damping. International journal of Electrical Power \& Energy Systems 29(3):241-250.

[8] Iyer, S., Ghosh, A. and Joshi, A., 2005. Inverter topologies for DSTATCOM applications-a simulation study. Electric Power Systems Research 75(32): $161-170$

[9] Schauder, C.D. and H. Mehta, 1993. Vector analysis and control of advanced static VAR compensators. IEEE Proceedings 140(4): $299-306$.

[10] Lehn, P.W. and M.R. Iravani, 1998. Experimental evaluation of STATCOM closed loop dynamics. IEEE Transactions on Power Delivery 13(4): 13781384.

[11] Fujita, H., Akagi, H. and Watanabe, Y., 2006. Dynamic control and performance of a unified power flow controller for stabilizing an AC transmission system. IEEE Transactions on Power Electronics 21(4): 1013-1020.

[12] El-Moursi, M.S. and A.M. Sharaf, 2006. Novel reactive power controllers for the STATCOM and SSSC. Electric Power Systems Research 76(4): 228241.

[13] Jower F.A., 2007, Improvement of synchronizing power and damoing power by means of SSSC and STATCOM: A comparative study. Electric Power Systems Research 77(8): 1112-1117.

[14] Applications, In Proceedings IEEE Power Engineering Society Winter Meeting. 1177-1183. Yankui, Z., Yan, Z., Bei, W, and Jian, Z., 2006. Power injection model of STATCOM with control and operating limit for power flow and voltage stability analysis. Electric Power Systems Research 76(12): 1003-1010.

[15] Hingorani, N. G. and L. Gygugyi, 2000. Understanding FACTS: Concepts and Technology of Flexible AC Transmission Systems. New York: IEEE Press.

[16] Sen, K.K., 199. STATCOM-STA Ticsynchronous COM Pensator: Theory, modeling, and O. Farrok. M.G. Rabbani and M.R. Islam/International Energy Journal 11(2010) 43-50. 